\title{
Rational Inattentiveness in a Forecasting Experiment
}

\author{
Henry Goecke ${ }^{a, b}, \quad$ Wolfgang J. Luhan ${ }^{c}, \quad$ Michael W.M. Roos ${ }^{c 1}$ \\ a TU Dortmund, Germany \\ b Cologne Institute for Economic Research, Germany \\ c Ruhr-University Bochum, Germany
}

\begin{abstract}
While standard theory assumes rational, optimizing agents under full information, the latter is rarely found in reality. Information has to be acquired and processed-both involving costs. In rationalinattentiveness models agents update their information set only when the benefit outweighs the information cost. We test the rational-inattentiveness model in a controlled laboratory environment. Our design is a forecasting task with costly information and a clear cost-benefit structure. While we find numerous deviations from the model predictions on the individual level, the aggregate results are clearly consistent with rational-inattentiveness and sticky information models rejecting simpler behavioral heuristics.
\end{abstract}

Keywords: experiment, information, rational inattentiveness, forecasting,

JELcodes: C53, C91, E10

\footnotetext{
${ }^{1}$ Corresponding Author: Institute for Macroeconomics \& Bochum Lab for Experimental Economics (RUBex), Faculty of Economics, Ruhr-University Bochum, Universitaetsstrasse 150, 44801 Bochum, Germany, +49 (0) 234/32-22886, michael.roos@rub.de
} 


\section{Introduction}

The assumption of fully informed decision makers who rationally optimize is a popular punching bag for behavioral economists. We pick up the aspect of full information: In many situations decision makers do not have the information they need for optimal decisions but must acquire this information first. Acquiring and processing information is costly so before the decision can be made the decision maker must solve the problem of how much information to acquire.

The economic standard approach to this problem is to assume that decision makers take decision and information costs into account and optimize over the optimization problem. This has been proposed in the context of expectation formation (see Feige and Pearce 1976, Conlisk 1988, Reis 2006a, 2006b, Sims 2003, 2006) and is also the idea of the literature on optimal search and stopping (see Rapoport and Tversky 1970, Weitzman 1979, Bikhchandani and Sharma 1996).

Behavioral economists have challenged this approach in the recent years, because optimization over optimization can lead to infinite regress problems (see Lipman and McCardle 1991, Conlisk 1996, Goldstein et al. 2001). Furthermore, many problems of optimal decision making are very complicated and in many cases do not even have an analytical solution. Given their limited cognitive abilities humans can only be boundedly rational which typically implies the use of simple heuristics instead of sophisticated optimization algorithms (Gigerenzer and Todd 1999, Selten 2001). Experimental research confirms that individual behavior in situations with decision costs is often better described by simple heuristics than by optimization (e.g. Hey 1982, Pingle 1992, Gabaix et al. 2006, Schunk and Winter 2009).

While the experimental findings that individuals use heuristics to make decisions are very convincing, there is the problem of what they imply for the modeling of average or aggregate behavior. There are many different heuristics that can be used to solve problems and which heuristics are used is highly case-specific and context-dependent. Furthermore, experiments show that even for the same task there is considerable heterogeneity among individuals regarding the heuristics they use (see Schunk and Winter 2009, Hommes 2011). Under these conditions it may be very implausible to use a single heuristic to describe the behavior of the average decision maker in an abstract market setting. Models with optimizing representative agents may still be a valid modeling choice, if they are not interpreted as descriptive models of individual behavior but merely as predictive models of aggregate behavior. The individual use of many different heuristics could generate aggregate results which are predicted by the optimization model if there is no systematic bias that affects all heuristics in the same way.

We use a laboratory experiment with costly information acquisition in which subjects have to forecast a stochastic process to test whether an optimization model can predict subjects' average information updating behavior. Our experiment is inspired by the models on rational inattentiveness 
(Sims 2003, 2006, Reis 2006a, Reis 2006b) in which maximizing producers or consumers do not use all available information in each period to form forecasts, because gathering and processing information is costly. In these models, rational agents update their information set only when the benefit of an improved forecast is high enough relative to the information cost. Otherwise they ignore potentially available information and use outdated information to make predictions.

These models are highly relevant for macroeconomics as they provide a justification for the sticky-information Phillips curve. Mankiw and Reis $(2002,2007)$ proposed the sticky-information Phillips curve as an alternative to the standard sticky-price Phillips curve. In sticky-information models subjects make choices in every period, but do not update their information set before each choice. As a consequence subjects form their expectations partly on the basis of out-dated information. The empirical evidence with respect to the validity of sticky-information models is mixed. Support for the sticky-information Phillips curve is reported in Döpke et al. (2008), Dupor et al. (2010), and Mankiw and Reis (2007) while Coibion (2010), Korenok (2008), and Korenok et al. (2010) find that the sticky-information models fit the data rather poorly. One problem that typically plagues these studies using aggregate data is that subjects' expectations are hard to measure and that their individual information sets are unobservable. Experiments are less affected by these informational problems and can provide additional evidence on the microfoundations of the stickyinformation Phillips curve.

We focus on the central implication of rational-inattentiveness models: subjects balance costs and benefits of information acquisition and processing and rationally ignore available information if the costs exceed the benefits. The lab experiment allows us to control the costs and benefits of information perfectly and to generate a clear theoretical benchmark of optimal behavior. In an individual choice experiment, subjects have to predict the realization of a simple stochastic process in several periods. In each period, subjects can choose between forecasting without new information (guessing) or buying information. All information is perfect providing the true value of the process in the current period. As the process is autocorrelated, information generates a positive but diminishing benefit for all future forecasts. ${ }^{2}$

Our aggregate results are consistent with rational inattentiveness. In the aggregate, observations are not significantly different from the model predictions, i.e. agents behave as if they are able to calculate the optimal length of inattention. Our alternative, a simple myopic heuristic, is not a good description of subjects' behavior. We find that subjects' responses to information costs

\footnotetext{
2 To our knowledge, there are no previous studies examining rational inattention experimentally except for Cheremukhin et al. (2011). The authors use data from repeated binary lottery choices to evaluate a rational inattention model and estimate risk attitudes as well as information costs, finding general support for their model.
} 
and to the nature of the process to be forecasted are in line with the theory. Individual forecasts, however, are often not optimal given the information set.

The remainder of the paper is organized as follows. Section 2 presents the theory and section 3 discusses the design and the hypothesis that will be tested. The experimental procedure is described in section 4. The results of the analysis can be found in Section 5. Finally, Section 6 concludes.

\section{Theory}

Rather than implementing a specific inattentiveness model from the theoretical literature, we designed a simple stylized model that captures the main idea of the rational-inattentiveness literature and allows us to derive the optimal information updating frequency easily. The essence of rational inattentiveness is that subjects weigh the benefits of new information against the costs of its acquisition. If the costs are higher than the expected benefit, they may rationally decide not to get the available information.

As one popular application of the rational-inattentiveness model is the sticky-information Phillips curve (Mankiw and Reis 2002), we chose a forecasting task to test for inattentiveness. In sticky-information Phillips curve models, subjects must form expectations about future prices and sometimes do so based on outdated information sets.

We model a situation in which subjects forecast realizations $p$ of a stochastic process. The stochastic process is a random walk in which the innovation $\varepsilon_{t}$ is limited to a fixed number of realizations drawn from a uniform distribution:

$$
p_{t}=p_{t-1}+\varepsilon_{t},
$$

with $\varepsilon_{\mathrm{t}} \in\left\{\mathrm{x}_{1}, \ldots, \mathrm{x}_{\mathrm{n}}\right\}$ and $\operatorname{prob}\left(x_{i}\right)=1 / \mathrm{n} \forall i$.

The initial value $p_{0}$ of the stochastic process is given, all possible realizations of the random walk for the whole forecast horizon and the corresponding probabilities $q_{j t}$ of each realization $j$ in each period $t$ can be calculated. Forecasting the realizations of the stochastic process reduces to guessing one of the possible values. The best forecast is the value with the highest probability $q_{t}^{*}$, which is decreasing in the number of periods between information updates. In each period $t$, agents choose whether to acquire information. Information is perfect, i.e. the agent observes the current realization of the process, $p_{t}$. The information costs are fixed and equal to $c$. If they do not acquire information they have to guess the current realization. Observing the realization is equivalent to guessing correctly. The more periods a participant does not update his information the more realizations of the random walk are possible and therefore $q_{t}^{*}$ decreases with inattentiveness. If $\varepsilon_{t}$ is drawn from a symmetric set with the expected value $0\left(E_{t} \varepsilon_{t}=0\right), E_{t-1} p_{t}=p_{t-1}$ is the best forecast.

In each period a correct guess generates a fixed payoff of $b$, an incorrect guess generates a payoff of 0 . Observing the realization generates a safe payoff $b-c$ while guessing results in an 
expected payoff $b \cdot q_{t}^{*}$. The certain payoff remains constant but the expected payoffs decline in the number of periods without an information update. This tradeoff between information costs and declining expected payoffs of guessing implies a deterministic optimal updating frequency.

Given a finite number of forecasting periods $N$, a risk neutral agent aiming to maximize expected payoffs will choose the updating frequency $T$ :

$$
T^{*}=\operatorname{argmax} E(\Pi(T))
$$

with

$$
E(\Pi(T))=\left\lfloor\frac{N}{T}\right\rfloor\left([b-c]+b \sum_{t=1}^{T-1} q_{t}^{*}\right)+b \sum_{t=1}^{N \bmod T} q_{t}^{*}
$$

The expected payoff contains the safe element $(b-c)$ which is earned whenever the subject buys information. The uncertain element $b \sum_{t=1}^{T-1} q_{t}^{*}$ results from guessing that value of $p$ which has the highest probability $q_{t}^{*}$ in period $t$ in which no information is acquired. $T-1$ is the length of inattentiveness between two updating periods resulting from the decision to update information every $T$ periods. We define $I \equiv T-1$. Within a finite number of $N$ periods, not every updating frequency $T$ is feasible without a remainder $(N \bmod T)$. In those remaining periods, it is optimal to guess based on the information set acquired in the last updating.

A rational, profit-maximizing agent would determine $T^{*}$ by computing and comparing expected profits in (3) for different updating frequencies $T$. It is difficult to provide a closed-form general solution to the problem of finding the optimal $T^{*}$, because of the complication that not every given $N$ is divisible by all potential $T$. It is clear that the optimal $T^{*}$ exists and depends positively on the costs $c$, the number of periods $N$, and the number $n$ of possible realizations of $\varepsilon_{t}$ which determines $q_{t}^{*}$. For a given set of parameters $T^{*}$ can be identified by iterative computation.

In our view, the difficulty to find an analytic solution for optimal behavior provides a strong test for the model. It is highly unlikely that subjects will compute the optimal updating frequency. If the model nevertheless describes the aggregate behavior of subjects, this is strong evidence that the as-if model can be useful even if cannot be interpreted literally.

It is more likely that agents do not behave in such a strict profit-maximizing way, but use some heuristic. A plausible heuristic might be myopic behavior by which agents do not take into account that updating information in the current period affects future expected values. Myopic subjects might perform a stepwise optimization rather than a complete one. Following this heuristic, subjects take into account the expected profits up to the period of the information update, but neglect the increased probability of a correct guess in future periods.

This approach produces a simple decision rule: myopic subjects are inattentive in a period $t$, if the expected payoff in that period exceeds the net payoff of acquiring information:

$$
q_{t}^{*} b>b-c
$$




\section{Design and Hypotheses}

The main question of our experiment is whether subjects' behavior in the given forecasting task is best predicted by rational inattentiveness or by myopic behavior. We test the null hypothesis that subjects behave in rationally inattentive way. By varying the variables $q^{*}, c$ and $N$ we generate different predictions of the updating frequency $T$ that allow us to test our null hypothesis against the alternative.

To keep the forecasting task as simple as possible, we at first limit $\varepsilon_{t}$ to two realizations, $\varepsilon_{t} \in$ $\{-1,+1\}$ with a commonly known initial value of $p_{0}=0$. The resulting probabilities for all possible realizations $p_{t}$ are summarized exemplarily for periods 0 to 4 in Table $1 .^{3}$ The probability of any given realization declines the further the respective period lies in the future.

Table 1: Probability distribution two-step random walk

\begin{tabular}{|c|c|c|c|c|c|c|c|c|c|c|}
\hline \multirow[b]{2}{*}{ Period } & \multicolumn{10}{|c|}{ Realizations $p$} \\
\hline & & -4 & -3 & -2 & -1 & 0 & 1 & 2 & 3 & 4 \\
\hline 0 & \multirow{5}{*}{ 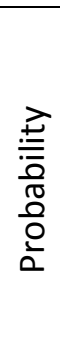 } & & & & & 1 & & & & \\
\hline 1 & & & & & 0.5 & 0 & 0.5 & & & \\
\hline 2 & & & & 0.25 & 0 & 0.5 & 0 & 0.25 & & \\
\hline 3 & & & 0.13 & 0 & 0.38 & 0 & 0.38 & 0 & 0.13 & \\
\hline 4 & & 0.06 & 0 & 0.25 & 0 & 0.38 & 0 & 0.25 & 0 & 0.06 \\
\hline
\end{tabular}

Table 2: Probability distribution: five-step random walk

\begin{tabular}{|c|c|c|c|c|c|c|c|c|c|c|}
\hline \multirow[b]{2}{*}{ Period } & \multicolumn{10}{|c|}{ Realizations $p$} \\
\hline & & -4 & -3 & -2 & -1 & 0 & 1 & 2 & 3 & 4 \\
\hline 0 & \multirow{5}{*}{$\begin{array}{l}\frac{\vec{z}}{\overline{\overline{0}}} \\
\frac{0}{\pi} \\
\frac{0}{0} \\
\frac{0}{2}\end{array}$} & & & & & 1 & & & & \\
\hline 1 & & & & 0.2 & 0.2 & 0.2 & 0.2 & 0.2 & & \\
\hline 2 & & 0.04 & 0.08 & 0.12 & 0.16 & 0.2 & 0.16 & 0.12 & 0.08 & 0.04 \\
\hline 3 & & 0.05 & 0.08 & 0.12 & 0.14 & 0.15 & 0.14 & 0.12 & 0.08 & 0.05 \\
\hline 4 & & 0.06 & 0.08 & 0.11 & 0.13 & 0.14 & 0.13 & 0.11 & 0.08 & 0.06 \\
\hline
\end{tabular}

The number of possible innovations of the random walk is our first treatment variable. To analyze whether a higher number of possible realizations induces a stronger deviation of observed behavior from the theoretical predictions and to test the comparative statics with respect to $n$, we

\footnotetext{
${ }^{3}$ The complete table, summarizing the probabilities for up to 20 periods, can be found in the online appendix.
} 
implement a second stochastic process where $\varepsilon_{t} \in\{-2,-1,0,1,2\}$. Table 2 presents the probabilities for realizations in the first 4 periods. ${ }^{4}$

The rational-inattentiveness model predicts agents to update their information set more frequently in the treatment with the five-step process than in the treatment with the two-step random walk because of the larger variance of the five-step process. This variation allows us to study the influence of $q^{*}$ in the determination of the updating frequency.

The payoff for correct predictions is fixed at $b=30$. In order to analyze the impact of information costs, our second treatment variable is $c$. The costs can be either lower than the payoff at $c=20$ and $c=26$, or higher than the payoff at $c=35$. This last parameterization was chosen to analyze whether subjects comprehend the fact that buying information might create a loss in the current period but increases the expected payoff in future periods.

Our third treatment variable is the number of forecasting periods $N$. We implement two process durations, $N=12$ and $N=20$. The calibration is such that the length of the process should hardly affect the updating frequency. Nevertheless subjects might believe that they should increase the length of updating intervals when there are more periods. These three treatment variables constitute a $2 \times 3 \times 2$ design that is summarized with the respective treatment numbers in Table 3 .

Table 3: Treatments

\begin{tabular}{c|c|c}
\hline \multicolumn{3}{c}{$\varepsilon_{\mathrm{t}} \in\{-1,1\}$} \\
\hline $\mathrm{N}=$ & 12 & 20 \\
\hline Model & \multicolumn{2}{c}{ Treatment } \\
\hline$b=30$ & 1 & 2 \\
$c=\mathbf{2 0}$ & & \\
\hline$b=30$ & 3 & 4 \\
$c=\mathbf{2 6}$ & & \\
\hline$b=30$ & 5 & 6 \\
$c=35$ & & \\
\hline
\end{tabular}

\begin{tabular}{c|c|c}
\hline \multicolumn{3}{c}{$\varepsilon_{\mathrm{t}} \in\{-2,-1,0,1,2\}}$, \\
\hline $\mathrm{N}=$ & \multicolumn{1}{c}{12} & 20 \\
\hline Model & \multicolumn{2}{|c}{ Treatment } \\
\hline$b=30$ & 7 & 8 \\
$\boldsymbol{c}=\mathbf{2 0}$ & & \\
\hline$b=30$ & 9 & 10 \\
$\boldsymbol{c}=\mathbf{2 6}$ & & \\
\hline$b=30$ & 11 & 12 \\
$\boldsymbol{c}=\mathbf{3 5}$ & & \\
\hline
\end{tabular}

With the parameterization in treatments $1-12$, we can calculate the optimal updating frequencies and the resulting length of inattentiveness between information purchases resulting from our competing models. Equations (2) and (3) produce the optimal updating frequencies that maximize the overall expected payoffs in each treatment. The corresponding optimal spans of inattentiveness $(I)$ are contained in the columns labeled "rational" in Table 4. The myopic heuristic generates different predictions which are shown in the column "myopic".

\footnotetext{
${ }^{4}$ Again, the complete table can be found in the online appendix..
} 
In addition to the point predictions for the average spans of inattention, we test the comparative statics of the model. This test includes variations in all three treatment variables $q^{*}, c$ and $N$. The rational-inattentiveness model predicts that the length of inattention does not decrease in $c$, will be lower or equal in the five-step process than in the two-step process and does not increase in $\mathrm{N}$.

\section{Procedure}

The experiment was implemented computerized using z-Tree (Fischbacher 2007) at the RUBex laboratory at the Ruhr-University Bochum. The 127 participants were students from economics and other fields of the Ruhr-University of Bochum.

Upon arrival in the lab, subjects were randomly seated at workstations separated by blinds. The instructions (see online appendix A) contained complete lists of probabilities for the respective processes for up to 20 periods. Instructions were read aloud and subjects were encouraged to ask questions at any point of the experiment. A comprehension test was conducted to assure that all participants had understood how to use the probability tables and how to calculate probabilities after an information purchase (online appendix C).

We implemented a within-subjects design with respect to changes in information costs and the number of periods. We decided to test the impact of the process between subjects, because a change of processes (or several changes) could have confused participants and might have resulted in mistakes from using the wrong probability table. Each subject therefore completed either treatments 1-6 or treatments 7-12. We implemented two different sequences of the treatments to check for possible order-effects. In sequence 1 the order for the two-step process was: 1,2,6,3,5,4 and the order for the five-step process was $7,8,12,9,11,10$. So for both of the processes the sequence of information costs and process durations were identical to foster comparability. In sequence 2 we reverted the orders: 4,5,3,6,2,1 and 10,11,9,12,8,7 respectively. We implemented 6 sessions with 87 participants in sequence 1 (41 subjects in the two-step and 46 in the five-step process) and 2 sessions with 40 participants in sequence 2 (20 subjects in each process).

One of the six treatments was chosen randomly at the end of the experiment and participants were paid for the sum of their accumulated profits in that treatment. As the maximal payoff in a 12 period treatment is 360 and in a 20 period treatment is 600 we normalized the payoffs by dividing the payoff by the number of periods in that treatment. The conversion rate was $2.5 €$ per normalized payoff point.

The theoretical model assumes risk neutrality, but subjects are generally risk averse (see, e.g., Dohmen et al. 2011, Holt and Laury, 2002). We hence measure risk aversion using the standard 9step categorical risk aversion measure as in Holt and Laury (2002). If subjects are risk averse, the 
frequency of information updates should ceteris paribus be higher than that of risk neutral subjects. The Holt-Laury risk aversion test was conducted at the end of the experiment and paid separately.

A session lasted on average 80 minutes, the average payoff (including a $4 €$ show up fee) was $25.1 €$, the maximal payoff was $51.6 €$, and the minimal payoff was $8.1 €$.

\section{Results}

Our main variable of interest is the average length of inattentiveness $I$ over all subjects in the individual treatments. For all following tests we first calculate the average length of inattention between two information updates for each subject in each treatment separately. The numbers for each treatment are the means of those averages.

As stated before, we implemented two different sequences of treatments to check for possible order effects. Using the Kolmogorov-Smirnov test we compared the distributions of the average durations of inattentiveness in identical treatments of sequence 1 and 2 and do not find significant differences in all but one pairwise comparison (treatment 7). However, if we use the $t /$ test to compare the average $I$ in the same treatments, but different orderings, we find significant differences in four cases (see table $4 a$ in the online appendix D). The observed duration of inattention becomes smaller in treatments $1,2,7$, and 8 if these treatments are moved from the beginning of the experiment to the end. Since the conclusions are the same, no matter whether we use sequence 1 or sequence 2 , the order effects detected by the t/test are not relevant for our analysis. We therefore feel safe to pool the observations from both sequences in the following analysis.

\subsection{Rational inattentiveness vs. myopic information acquisition}

Table 4 contains the average number of periods $I$ in which subjects do not acquire new information in the different treatments. The mean-comparison tests show that in 7 of 12 cases the mean duration of inattention is not significantly different from the rational prediction at the $5 \%$ level. In contrast, the observed duration is significantly different from the prediction of the myopic heuristic in all treatments. The myopic heuristic predicts that subjects should never acquire any information if $c \geq 30$ which we do not observe in any of the concerned treatments. The myopic heuristic predicts that subjects should never acquire any information if $c \geq 30$ which we do not observe in any of the concerned treatments. The myopic heuristic does not appear to describe subjects' average information acquisition behavior. 
Table 4: Average duration of inattentiveness

Process: $\varepsilon_{t} \in\{-\mathbf{1}, \mathbf{1}\}$

\begin{tabular}{c|c|c|c|c|c|c|c|c}
\hline $\mathrm{N}=$ & \multicolumn{5}{c|}{12} & \multicolumn{4}{c}{20} \\
\hline $\mathrm{c}$ & Treat. & Rational & Myopic & $I$ & Treat. & Rational & Myopic & $I$ \\
\hline 20 & 1 & 2 & $4 *$ & $\begin{array}{c}2.09 \\
(0.24)\end{array}$ & 2 & 2 & $4 *$ & $\begin{array}{c}2.70 \\
(0.48)\end{array}$ \\
\hline 26 & 3 & $4 *$ & $12 *$ & $\begin{array}{c}2.67 \\
(0.35)\end{array}$ & 4 & 2 & $20^{*}$ & $\begin{array}{c}2.79 \\
(0.46)\end{array}$ \\
\hline 35 & 5 & $6 *$ & $12 *$ & $\begin{array}{c}4.52 \\
(0.48)\end{array}$ & 6 & 6 & $20^{*}$ & $\begin{array}{c}5.79 \\
(0.77)\end{array}$ \\
\hline
\end{tabular}

Process: $\varepsilon_{\mathrm{t}} \in\{-2,-1,0,1,2\}$

\begin{tabular}{c|c|c|c|c|c|c|c|c}
\hline $\mathrm{N}=$ & \multicolumn{5}{c|}{12} & \multicolumn{4}{c}{20} \\
\hline $\mathrm{c}$ & Treat. & Rational & Myopic & $l$ & Treat. & Rational & Myopic & $I$ \\
\hline 20 & 7 & $0^{*}$ & $0^{*}$ & $\begin{array}{c}1.45 \\
(0.25)\end{array}$ & 8 & $0^{*}$ & $0^{*}$ & $\begin{array}{c}1.61 \\
(0.34)\end{array}$ \\
\hline 26 & 9 & 2 & $4 *$ & $\begin{array}{c}1.71 \\
(0.23)\end{array}$ & 10 & 2 & $4 *$ & $\begin{array}{c}1.97 \\
(0.35)\end{array}$ \\
\hline 35 & 11 & 6 & $12 *$ & $\begin{array}{c}6.42 \\
(0.52)\end{array}$ & 12 & $6 *$ & $20^{*}$ & $\begin{array}{c}9.70 \\
(0.93)\end{array}$
\end{tabular}

Notes: The columns "l" contain the mean number of periods without information update, standard errors in parentheses. c: cost of information purchase, Rational: duration of inattentiveness predicted by rationalinattentiveness model, Myopic: duration of inattentiveness predicted by myopic heuristic, ${ }^{*}$ indicates difference between means and predictions at 5\% (or below) significance level from two-tailed t-tests.

Three of the five rejections of the rational prediction occur in the treatments with the five-step process. This is not surprising as this process is more complicated than the two-step process. In particular, subjects to not recognize that they should buy information in every period, when the cost of information is low. An obvious suspicion is that the model predictions are rejected because the model assumption of risk-neutral subjects is violated. The Holt-Laury test produced the standard result that most subjects are moderately risk averse. Out of the 112 subjects for whom the HoltLaury task produce consistent results, 4 subjects (3.6\%) are classified as risk loving with a Holt-Laury score below $4.17(15.2 \%)$ are risk neutral, and $81.2 \%$ are risk averse (Holt-Laury score $>4$ ) as it is common in the literature. The violation of risk neutrality cannot explain our findings, because a riskaverse subject would update the information set more frequently than a risk-neutral individual, but we do not observe that subjects acquire information more often than predicted by the model under the assumption of risk neutrality. We find that the subjects in treatments 7,8 , and 12 purchase information even less frequently than would be optimal. Comparing risk averse subjects with risk neutral and risk loving subjects, we find significant differences $(p<0.1)$ in the average duration of inattention only in 2 out of the 12 treatments. 
Table 5: Change in duration of inattention Effect of information costs $c$

\begin{tabular}{|c|c|c|c|}
\hline Treatments & Means & $\begin{array}{c}\text { Rational } \\
\text { prediction }\end{array}$ & $p$-value \\
\hline $\begin{array}{l}1 \text { vs. } 3 \\
(20 / 26) \\
\end{array}$ & 2.08 vs. 2.67 & $<$ & 0.09 \\
\hline $\begin{array}{l}\text { vs. } 5 \\
\text { (26/35) }\end{array}$ & 2.67 vs. 4.52 & $<$ & $<0.01$ \\
\hline $\begin{array}{l}1 \text { vs. } 5 \\
(20 / 35)\end{array}$ & 2.08 vs. 4.52 & $<$ & $<0.01$ \\
\hline $\begin{array}{l}2 \text { vs. } 4 \\
(20 / 26)\end{array}$ & 2.70 vs. 2.79 & $=$ & 0.89 \\
\hline $\begin{array}{l}4 \text { vs. } 6 \\
(26 / 35)\end{array}$ & 2.79 vs. 5.79 & $<$ & $<0.01$ \\
\hline $\begin{array}{l}2 \text { vs. } 6 \\
(20 / 35)\end{array}$ & 2.70 vs. 5.79 & $<$ & $<0.01$ \\
\hline $\begin{array}{l}7 \text { vs. } 9 \\
(20 / 26)\end{array}$ & 1.44 vs. 1.71 & $<$ & 0.22 \\
\hline $\begin{array}{l}9 \text { vs. } 11 \\
(26 / 35)\end{array}$ & 1.71 vs. 6.42 & $<$ & $<0.01$ \\
\hline $\begin{array}{l}7 \text { vs. } 11 \\
(20 / 35)\end{array}$ & 1.44 vs. 6.42 & $<$ & $<0.01$ \\
\hline $\begin{array}{l}8 \text { vs. } 10 \\
(20 / 26)\end{array}$ & 1.62 vs. 1.97 & $<$ & 0.24 \\
\hline $\begin{array}{c}10 \text { vs. } 12 \\
(26 / 35)\end{array}$ & 1.97 vs. 9.70 & $<$ & $<0.01$ \\
\hline $\begin{array}{l}8 \text { vs. } 12 \\
(20 / 35)\end{array}$ & 1.62 vs. 9.70 & $<$ & $<0.01$ \\
\hline
\end{tabular}

Effect of process type

\begin{tabular}{|c|c|c|c|}
\hline $\begin{array}{c}1 \text { vs. } 7 \\
(2 / 5)\end{array}$ & 2.08 vs. 1.45 & $>$ & 0.03 \\
\hline $\begin{array}{c}2 \text { vs. } 8 \\
(2 / 5)\end{array}$ & 2.70 vs. 1.62 & $>$ & 0.03 \\
\hline $\begin{array}{c}3 \text { vs. } 9 \\
(2 / 5)\end{array}$ & 2.67 vs. 1.71 & $>$ & 0.01 \\
\hline $\begin{array}{c}4 \text { vs. } 10 \\
(2 / 5)\end{array}$ & 2.79 vs. 1.97 & $=$ & 0.16 \\
\hline $\begin{array}{c}5 \text { vs. } 11 \\
(2 / 5)\end{array}$ & 4.52 vs. 6.41 & $=$ & $<0.001$ \\
\hline $\begin{array}{c}6 \text { vs. } 12 \\
(2 / 5)\end{array}$ & 5.79 vs. 9.70 & $=$ & $<0.001$ \\
\hline
\end{tabular}

Effect of process length $N$

\begin{tabular}{|c|c|c|c|}
\hline $\begin{array}{c}1 \text { vs. } 2 \\
(12 / 20)\end{array}$ & 2.08 vs. 2.70 & $=$ & 0.25 \\
\hline $\begin{array}{c}3 \text { vs. } 4 \\
(12 / 20)\end{array}$ & 2.67 vs. 2.79 & $>$ & 0.58 \\
\hline $\begin{array}{c}5 \text { vs. } 6 \\
(12 / 20)\end{array}$ & 4.52 vs. 5.79 & $=$ & 0.16 \\
\hline $\begin{array}{c}7 \text { vs. } 8 \\
(12 / 20)\end{array}$ & 1.44 vs. 1.62 & $=$ & 0.69 \\
\hline $\begin{array}{c}9 \text { vs. } 10 \\
(12 / 20)\end{array}$ & 1.71 vs. 1.97 & $=$ & 0.55 \\
\hline $\begin{array}{c}11 \text { vs. } 12 \\
(12 / 20)\end{array}$ & 6.42 vs. 9.70 & $=$ & $<0.001$ \\
\hline
\end{tabular}

$p$-values from two-tailed t-tests, treatment differences in parenthesis, bold face numbers indicate a confirmation of the theoretical prediction 
Using pairwise treatment comparisons we can test the predictions of the rational inattentiveness model. When comparing treatments that only differ in the information costs we should find that the length of inattention increases in $c$ for all but one comparison - see the top panel of table 5. Likewise, the five-step process should decrease the length of inattention in three treatment comparisons and have no effect in the remaining three comparisons. Finally, the length of the process should have no effect on the length of inattention, except for the comparison between treatments 3 and 4 . Table 5 shows that the model predictions cannot be rejected in 17 out of the 24 cases. While subjects always adjust their inattentiveness correctly when the cost of information changes from intermediate to high, they do not adjust correctly in three out of the four cases in which low and intermediate information costs are compared.

So far we compared the average behavior of all subjects with the model predictions and found that the average behavior is quite consistent with the theory. An interesting question is whether the averages fit the theory because individual deviations from optimal behavior in both directions happen to cancel out. Figure 1 presents histograms of the average inattentiveness of the subjects in the different treatments. The solid line represents the average of all subjects and the dashed line stands for the rational prediction. The histograms show that in most cases the individual durations of inattentiveness within one treatment display little variance and deviate only slightly from the theoretical prediction. Obvious exceptions are treatments 5, 6, 11, and 12 in which the costs of information are higher than the immediate payoff. In these treatments, many subjects acquire information too often, but the average inattentiveness is corrected upwards by a significant fraction of subjects that never buy information. The shares of subjects that never buy information in the highcost treatments and thus follow the myopic heuristic are 18\% and 13\% in treatments 5 and 6 and $33 \%$ and $30 \%$ in treatments 11 and 12 . Especially the high-cost treatments show that the aggregate statistics hide some heterogeneity in individual behavior.

Although the design of our treatments allows for ceteris paribus inference tests as depicted in Table 5, a Tobit regression of the mean length of inattention on the treatment variables and a few controls may be informative $e^{5} . \Delta c$ is a categorical variable equal to 0 if $c=20$, equal to 1 if $c=26$ and equal to 2 if $c=35$. 5-step and $\mathrm{N}=20$ are dummy variables equal to 1 for the five-step process and the longer process. RA is the Holt-Laury risk aversion score of each individual, female and smoker are dummy variables. Table 6 contains the results from different specifications of the Tobit estimation.

The regressions confirm two predictions of the rational model. The average length of inattention increases with higher information costs, but does not increase with the variance of the stochastic process as the dummy for the five-step process is insignificant. Subjects are more inattentive if $N$ is equal to 20 instead of 12 contradicting the model.

\footnotetext{
${ }^{5}$ Since we have a within-subjects design the observations of the same subjects are not independent across treatments. We therefore estimate robust standard errors that allow for a violation of independence for the observations of the same subjects (clustered sandwich estimator).
} 
Not surprisingly, more risk-averse subjects are less inattentive, as indicated by the negative coefficient on RA. In our first specification (1), we included a dummy for female participants and find that women are more inattentive than men.

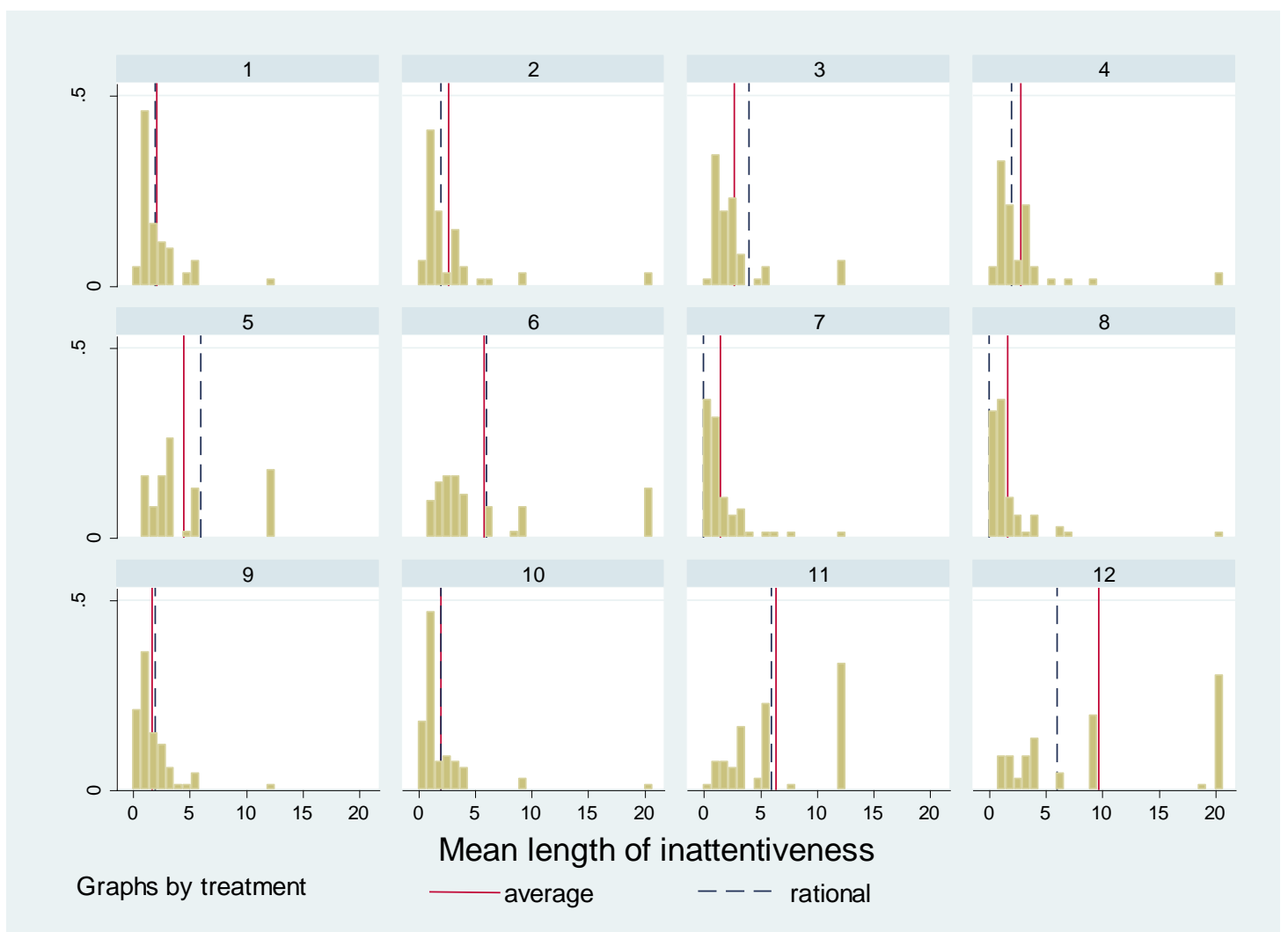

Figure 1: Distribution of individual durations of inattentiveness by treatment

The dummy for smokers-which is a common proxy for forward-orientation or planning behavior ${ }^{6}-$ is not significantly different from zero in model (1). We find that women are more inattentive than men even though the results from the Holt-Laury task indicate that the female participants are slightly more risk averse than men. The mean of the Holt-Laury score is 5.6 for men and 6.18 for women in our sample and the difference is significant in a one-sided t-test at $p=0.051$. Being more risk-averse, one would expect women to buy information more often than men. One potential explanation would be that the observed gender difference is simply unrelated to risk aversion. Another explanation four our contradictory result might be that the Holt-Laury procedure misrepresents women's true risk preferences ${ }^{7}$. Eckel and Grossman (2008) argue that in laboratory experiments the measured risk preference often depends on the elicitation method. In order to check whether the estimated gender difference is just an artifact of the risk-aversion measure, we exclude each of the respective variables in additional estimations (columns (2) and (3) of table 6) and estimate the model separately for women (column (4) of table 6) and men (column (5)).

\footnotetext{
${ }^{6}$ See, e.g., Becker and Mulligan (1997), Khwaja et al. (2007).

${ }^{7}$ We thank the coeditor for bringing this point to our attention.
} 
Table 6: Tobit estimation, mean length of inattention

\begin{tabular}{|c|c|c|c|c|c|}
\hline & (1) & (2) & (3) & (4) & (5) \\
\hline Const & $\begin{array}{c}1.44 \\
(1.07)\end{array}$ & $\begin{array}{c}-0.61 \\
(0.51)\end{array}$ & $\begin{array}{c}1.70 \\
(1.13) \\
\end{array}$ & $\begin{array}{l}4.23^{*} \\
(2.21)\end{array}$ & $\begin{array}{c}0.20 \\
(0.87) \\
\end{array}$ \\
\hline$\Delta \mathbf{c}$ & $\begin{array}{c}2.85^{* * *} \\
(0.34)\end{array}$ & $\begin{array}{c}2.85 * * * \\
(0.34)\end{array}$ & $\begin{array}{c}2.85 * * * \\
(0.34)\end{array}$ & $\begin{array}{c}2.96 * * * \\
(0.50)\end{array}$ & $\begin{array}{c}2.71 * * * \\
(0.46)\end{array}$ \\
\hline 5-step & $\begin{array}{c}-0.40 \\
(0.59)\end{array}$ & $\begin{array}{c}-0.41 \\
(0.60)\end{array}$ & $\begin{array}{c}-0.35 \\
(0.59)\end{array}$ & $\begin{array}{c}-0.67 \\
(1.07) \\
\end{array}$ & $\begin{array}{l}-0.29 \\
(0.56)\end{array}$ \\
\hline$N=20$ & $\begin{array}{c}1.19 * * * \\
(0.27)\end{array}$ & $\begin{array}{c}1.19 * * * \\
(0.27)\end{array}$ & $\begin{array}{c}1.19 * * * \\
(0.27)\end{array}$ & $\begin{array}{c}1.66 * * * \\
(0.50)\end{array}$ & $\begin{array}{c}0.76^{* * *} \\
(0.24)\end{array}$ \\
\hline RA & $\begin{array}{c}-0.37^{* *} \\
(0.18)\end{array}$ & & $\begin{array}{c}-0.30 * \\
(0.17)\end{array}$ & $\begin{array}{c}-0.62 * * \\
(0.30)\end{array}$ & $\begin{array}{c}-0.09 \\
(0.14)\end{array}$ \\
\hline female & $\begin{array}{c}1.40 * * \\
(0.60)\end{array}$ & $\begin{array}{c}1.22^{* * *} \\
(0.58)\end{array}$ & & & \\
\hline smoker & $\begin{array}{c}-0.91 \\
(0.69) \\
\end{array}$ & $\begin{array}{c}-1.29 * * \\
(0.61)\end{array}$ & $\begin{array}{l}-0.91^{*} \\
(0.52)\end{array}$ & $\begin{array}{l}-1.87^{*} \\
(1.02)\end{array}$ & $\begin{array}{c}0.06 \\
(0.48)\end{array}$ \\
\hline Ps $R^{2}$ & 0.05 & 0.04 & 0.04 & 0.04 & 0.06 \\
\hline Obs. & 672 & 672 & 672 & 336 & 336 \\
\hline & all & all & all & females & males \\
\hline
\end{tabular}

Notes: $* * *, *$ significantly different from zero at $1 \%, 5 \%$, and $10 \%$ respectively, standard errors adjusted for subject cluster effects in parentheses. Due to inconsistent choices in the Holt-Laury (2002) risk aversion test, RA could not be calculated for 15 subjects.

We find that the results from the first regression do not change strongly if we exclude either the measure of risk aversion or the female dummy. The separate estimations reveal some differences between men and women. While the response in inattentiveness to changes of information costs and to the type of the stochastic process are identical, women increase the inattentiveness spans more than men if $\mathrm{N}=20$. Furthermore, the constant is much larger for women than for men and the risk-aversion measure is significantly negative for women, but not for men. Notice, however, that at the mean of female risk aversion (6.18), the effect of risk aversion on inattentiveness cancels out against the constant. This implies that at the mean level of risk aversion, the average duration of inattentiveness is the same for both sexes (neglecting the weakly significant dummy for smokers in the female group).

\subsection{Optimality of forecasts}

Subjects' task in this experiment was twofold. They had to decide when to acquire information and to use this information to make forecasts. The best forecast is the realization of the stochastic process with the highest probability (see tables 1 and 2). With the two-step process the best forecasts alternates between the last observed realization $p_{t-j}$ and $p_{t-j} \pm 1$. With the five-step process, the best prediction in the period after an information purchase is any of the five possible realizations and thereafter the value of the last observation. 

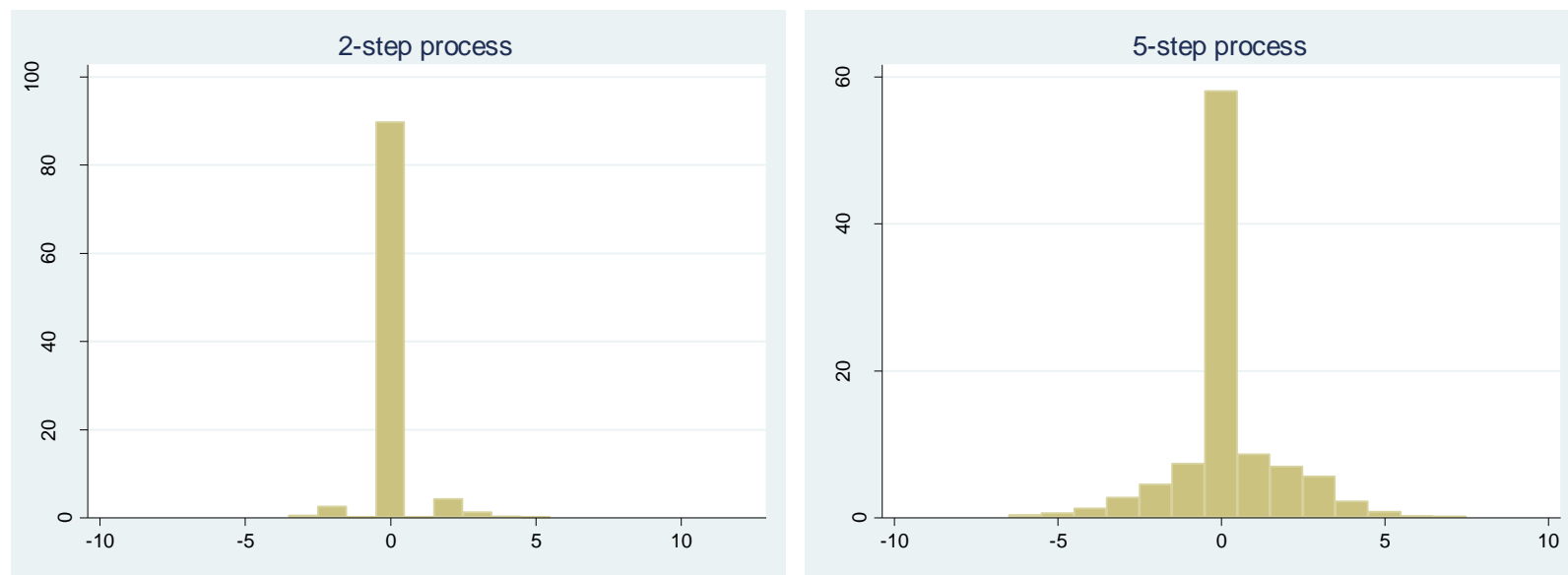

Figure 2: Histogram of deviations from optimal forecasts. Left two-step, right five-step process

Figure 2 shows the distribution of individuals' deviations from the optimal forecasts. More than $80 \%$ of all forecasts of the two-step process were optimal and almost $60 \%$ of the five-step forecast. One can also observe that the distribution of errors is symmetric around zero in both cases.

Table 7 shows the percentages of optimal forecasts in the periods after a subject had acquired the last information about the state of the stochastic process. In the first period without updated information, more than $98 \%$ of all forecasts are optimal for both processes. This is reassuring as any forecast of feasible values is optimal in the first period with outdated information. From the second period after an information purchase on there are differences in the forecasting behavior in the treatments with the two-step process and the five-step process.

Table 7: Optimal forecasts in periods after information acquisition

\begin{tabular}{ccc}
\hline & two-step & five-step \\
\hline $\mathbf{t + 1}$ & $1640 / 1660=98.8 \%$ & $1234 / 1250=98.7 \%$ \\
$\mathbf{t + 2}$ & $472 / 851=55.5 \%$ & $189 / 618=30.6 \%$ \\
$\mathbf{t + 3}$ & $369 / 456=80.9 \%$ & $113 / 359=31.5 \%$ \\
$\mathbf{t + 4}$ & $125 / 233=53.6 \%$ & $82 / 224=36.6 \%$ \\
$\mathbf{t + 5}$ & $101 / 138=73.2 \%$ & $54 / 157=34.4 \%$ \\
\hline
\end{tabular}

Subjects confronted with the two-step process make more optimal forecasts than those with the five-step process. We observe the pattern that the percentage of correct forecasts is higher in odd periods after an information purchase than in even periods, which is because there are two optimal forecasts in these periods and only one in the others. Only about one third of the forecasts of the five-step process more than one period after an information purchase are optimal.

Although the forecasting problem in this experiment is relatively simple, especially because every participant had a table with the probabilities of all possible realizations of the stochastic 
process, the large fraction of suboptimal forecasts suggests that many subjects did not understand what the optimal forecasting strategy was. Since it is even more difficult to determine the optimal frequency of information acquisition, it appears quite unlikely that the majority of subjects had an idea how to find the optimal degree of inattention or even that there is an optimum.

\section{Conclusion}

The main question of this paper is whether the average information acquisition behavior in a simple forecasting experiment can be predicted by a model of rational inattentiveness. According to the model, subjects should compare the benefits and costs of acquiring information which leads to optimal information updating frequencies that depend on the cost of information and the variance of the stochastic process to be predicted. We find that the aggregate information acquisition of all subjects is well predicted by the model. However, subjects also respond to the length of the stochastic process in a way that contradicts the model predictions. We also find that there is considerable heterogeneity in individual behavior which can be partially explained by gender and risk aversion.

Given the respective information sets, subjects' forecasts are often not optimal. Whereas subjects make optimal forecasts of the two-step process in $53-81 \%$ of all cases, forecasts of the fivestep process are not optimal in about two thirds of the cases. The assumption of optimization is hence not a good description of individual behavior, which is in line with previous experimental findings.

At least for our simple experiment, a model of rational inattentiveness can be considered as a reasonable as-if model of average behavior, even though many individuals do not optimize. Whether similar results hold in more complicated settings, remains to be shown. We do not want to challenge the view that individuals typically use heuristics when making decisions, but the use of heuristics at the individual level might not be visible in aggregate data unless a large number of individuals use the same heuristic or different heuristics that generate similar decisions. How well aggregate data can be described by heuristics is an interesting question for future research. 


\section{References}

Becker, Gary and Casey Mulligan (1997): The endogenous determination of time preference. Quarterly Journal of Economics 112(3), pp. 729-58.

Bikhchandani, Sushil and Sunil Sharma (1996): Optimal search with learning. Journal of Economic Dynamics and Control 20 ( 1-3), pp. 333-359.

Cheremukhin, Anton, Anna Popova, and Antonella Tutino (2011): Experimental evidence on rational inattention. Working paper 1112, Federal Reserve Bank of Dallas.

Coibion, Oliver (2010): Testing the sticky information phillips curve. The Review of Economics and Statistics 92 (1), pp. 87-101.

Conlisk, John (1988): Optimization cost. Journal of Economic Behavior and Organization 9 (3), pp. 213-228.

Conlisk, John (1996): Why bounded rationality? Journal of Economic Literature 34 (2), pp. 669-700.

Döpke, Jörg, Jonas Dovern, Ulrich Fritsche, and Jirka Slacalek (2008): The dynamics of european inflation expectations. The B.E. Journal of Macroeconomics 8 (1), pp. 1635-1690.

Dohmen, Thomas, Armin Falk, David Huffmann Uwe Sund, Jürgen Schupp and Gert Wagner (2011). Individual risk attitudes: Measurement, deterinants, and behavioral consequences. Journal of the European Economic Association 9(3), pp. 522-550.

Dupor, Bill, Tomiyuki Kitamura, and Takayuki Tsuruga (2010): Integrating sticky prices and sticky information. The Review of Economics and Statistics 92 (3), pp. 657-669.

Eckel, Catherine and Philip J. Grossman (2008): Men, women and riskaversion. In: Charles R. Plott and Vernon L. Smith, Editor(s), Handbook of Experimental Economics Results, Elsevier, pp. 10611073.

Feige, Edgar L. and Douglas Pearce (1976): Economically rational expectations: Are innovations in the rate of inflation independent of innovations in measures of monetary and fiscal policy? Journal of Political Economy 84 (3), pp. 499-522.

Fischbacher, Urs (2007): z-tree: Zurich toolbox for ready-made economic experiments. Experimental Economics 10 (2), pp. 171-178.

Gabaix, Xavier, David Laibson, Guillermo Moloche, and Stephen Weinberg (2006): Costly information acquisition: Experimental analysis of a boundedly rational model. American Economic Review 96 (4), pp. 1043-1068. 
Gigerenzer, Gerd, Peter Todd, and the ABC Research Group (1999): Simple heuristics that make us smart. Oxford University Press, New York.

Goldstein, Daniel G., Gerd Gigerenzer, Robin M. Hogarth, Alex Kacelnik, Yaakov Kareev, Gary Klein, Laura Martignon, John W. Payne, Karl H. Schlag (2001). Why and when do simple heuristics work? In: Gerd Gigerenzer and Reinhard Selten (eds.). Bounded Rationality - The Adaptive Toolbox. MIT Press, Cambridge.

Holt, Charles and Susan Laury (2002): Risk aversion and incentive effects. American Economic Review $92(5)$, pp. 1644-1655.

Hommes, Cars (2011): The heterogeneous expectations hypothesis: Some evidence from the lab. Journal of Economic Dynamics and Control 35 (1), pp. 1-24.

Hey, John (1982): Search for rules for search. Journal of Economic Behavior and Organization 3 (1), pp. $65-81$.

Khwaja, Ahmed, Dan Silverman, and Frank Sloan (2007): Time preference, time discounting, and smoking decisions. Journal of Health Economics 26(5), pp. 927-949.

Korenok, Oleg (2008): Empirical comparison of sticky price and sticky information models. Journal of Macroeconomics 30 (3), pp. 906-927.

Korenok, Oleg, Stanislav Radchenko, and Norman Swanson (2010): International evidence on the efficacy of new-keynesian models of inflation persistence. Journal of Applied Econometrics 25 (1), pp. 31-54.

Lippman, Steven and Kevin McCardle (1991) Uncertain search: A model of search among technologies of uncertain values. Management Science 37 (11), pp. 1474-1490.

Mankiw, Gregory and Ricardo Reis (2002): Sticky information versus sticky prices: A proposal to replace the New Keynesian Phillips curve. The Quarterly Journal of Economics 117 (4), 12951328.

Mankiw, Gregory and Ricardo Reis (2007): Sticky information in general equilibrium. Journal of the European Economic Association 5 (2-3), pp. 603-613.

Pingle, Mark (1992): Costly optimization: an experiment. Journal of Economic Behavior and Organization 17 (1), pp. 3-30.

Rapoport, Ammon and Amos Tversky (1970): Choice behavior in an optional stopping task. Organizational Behavior and Human Performance 5 (2), pp. 105-120.

Reis, Ricardo. (2006a): Inattentive consumers. Journal of Monetary Economics 53 (8), pp. 1761-1800. 
Reis, Ricardo (2006b): Inattentive producers. Review of Economic Studies 73 (3), pp. 793-821.

Schunk, Daniel and Joachim Winter (2009): The relationship between risk attitudes and heuristics in search tasks: A laboratory experiment. Journal of Economic Behavior and Organization 71 (2009), pp. 347-360.

Selten, Reinhard (2001). What is bounded rationality? In: Gerd Gigerenzer and Reinhard Selten (eds.). Bounded Rationality - The Adaptive Toolbox. MIT Press, Cambridge.

Sims, Christopher (2006): Implications of rational inattention. Journal of Monetary Economics 50(3): pp. 665-690.

Sims, Christopher (2006): Rational inattention: Beyond the linear-quadratic case. American Economic Review 92 (2), pp. 158-163.

Weitzman, Martin (1979): Optimal search for the best alternative. Econometrica 47 (3), pp. 641-654. 


\section{Online-Appendices}

\section{Appendix A: Instructions (two-step process)}

Welcome to the experiment. Please do not talk to any other participant from now on. We kindly ask you to use only those functions of the PC that are necessary for the conduct of the experiment.

The purpose of this experiment is to study decision behavior. You can earn real money in this experiment. Your payment will be determined solely by your own decisions according to the rules on the following pages.

The data from the experiment will be anonymized and cannot be related to the identities of the participants. Neither the other participants nor the experimenter will find out which choices you have made and how much you have earned during the experiment.

This experiment consists of two independent parts. You will receive the instructions for part two, after part one is finished.

\section{Part 1}

\section{Task}

In this experiment, you have to forecast a variable $\boldsymbol{p}$ which varies randomly. Your payoff in Euro at the end of the experiment depends on your number of correct forecasts.

\section{Procedure}

This sub experiment consists of six independent rounds. Each round consists of a fixed number of periods. Your task is to forecast the value of the variable $p$ in the current period. The number of periods in any given round may vary and will be displayed on the screen at the beginning of each round.

\section{Random process}

The variable $p$ starts with a value of 0 in period 0 . The variable $p$ is determined by a simple random process: The variable $p$ can change between the current period and the previous one by:

- $\quad$ rise by $1(+1)$

- decline by $1(-1)$

Both events are equally probable. The potential events, +1 and -1 , will therefore occur with $50 \%$ probability. Changes of the variable are independent over periods, i.e. both changes have the same probability independent of the change in the previous period.

To illustrate the process you receive a table containing all possible changes of $p$ in each round (see table 1 in the appendix). Please have a look at this table now. Each row represents a period; the columns show all possible values of $p$ during a 20-period process. Each cell contains the probability of the respective realization in the respective period. 


\section{Example:}

Take a look at this table:

\begin{tabular}{|c|c|c|c|c|c|c|c|c|c|c|}
\hline \multirow[b]{2}{*}{ Period } & \multicolumn{10}{|c|}{ Realizations of $p$} \\
\hline & & -4 & -3 & -2 & -1 & 0 & 1 & 2 & 3 & 4 \\
\hline 0 & & & & & & 1.000 & & & & \\
\hline 1 & $\stackrel{\underline{\underline{E}}}{\overline{\bar{n}}}$ & & & & 0.500 & 0 & 0.500 & & & \\
\hline 2 & 吕 & & & 0.250 & 0 & 0.500 & 0 & 0.250 & & \\
\hline 3 & 은 & & 0.125 & 0 & 0.375 & 0 & 0.375 & 0 & 0.125 & \\
\hline 4 & $a$ & 0.063 & 0 & 0.250 & 0 & 0.375 & 0 & 0.250 & 0 & 0.063 \\
\hline
\end{tabular}

You know with certainty that the value of the variable $p$ will be 0 in period 0 , i.e. the probability is 1 . The variable will change from period 0 to period 1 by +1 or -1 , both with the same probability of $50 \%$ $(=0.5)$. The same holds true for the change between periods 1 and 2 , again the variable can change by +1 or -1 . Therefore, the realizations of $p$ in period 2 can range between +2 and -2 .

The probability for a value +2 in period 2 is for example $25 \%(=0.25)$. This is due to the fact that a value of 2 in period 2 can only be realized if the value of $p$ was 1 in period 1 and rises by 1 between periods 1 and 2 . Therefore the probability is given by $0.5 \times 0.5=0.25$. The table in the appendix contains all probabilities for each possible realization of the variable $p$ in each period-thus you do not have to calculate the probabilities yourself.

\section{Forecast}

You have to enter your forecast for $p$ in the current period in an entry-box on the screen. You will be informed whether your forecasts were correct only after all 6 rounds are concluded at the end of the experiment.

\section{Information}

You know that the initial value of variable $p$ is 0 at the beginning of each round. In each period, you can buy information about the current value of $p$. This information costs you $c$ points. The costs $c$ may vary between the rounds but stay fixed within a round and will be displayed on screen. If you buy information, you learn the exact current realization of $p$ and your forecast is automatically correct without the necessity to enter a value.

\section{Earnings}

For each period with a correct forecast for the realization of $p$ you will earn $\boldsymbol{b}$ points. The earnings $b$ can vary between the rounds but stay fixed within a round and are displayed on screen. For an incorrect forecast of $p$ you earn 0 points.

All period-earnings in each round will be summed and the costs for all information purchases will be subtracted. Please note that in each round you can incur losses if the sum of information costs is higher than the sum of earnings.

\section{Example:}

Assume a round consisting of 10 periods, the earnings for a correct forecast in each period are $b=5$ and the information costs are $c=1$. You bought information in three periods and you made three additional correct forecasts. Of the ten realizations you therefore forecasted 6 correctly and 4 incorrectly. Your total earnings in this round are: $6 \times b+4 \times 0-3 \times c=6 \times 5-3 \times 1=27$. 


\section{Payoff}

Firstly, you earn a fixed participation fee of 4 euro. Your payoff in euro for this first part of the experiment depends on your earnings in one, randomly determined, round. At the end of the experiment you will be informed about the quality of your forecasts and the resulting earnings for each round. A random draw will determine which round was chosen for the calculation of your payoff. Your earnings (in points) will be converted to euro according to the following equation:

$$
\text { Payoff }=\frac{\text { total earnings from randomly choosen round }}{\text { number of periods }} \times 2.5 \mathrm{EUR}
$$

\section{Example:}

Assume the round from the example above was drawn do determine your payoff. The earnings were 27 and the number of periods 10. Your payoff would therefore be 6.75 EUR.

\section{Calculator}

If you need a calculator you can open the Windows-calculator by clicking on the symbol in the bottom left corner of the screen.

\section{Time}

The time limit for each round is 5 minutes. The remaining time is displayed (in seconds) at the top part of the screen.

\section{Trial}

Before the part 1 starts, there will be a trial round consisting of 10 periods with a time limit of 10 minutes. The trial round has the same structure as the experiment, except for the number of periods and the time limit. The results from the trial do not affect your final payoffs.

\section{Comprehension test}

Please answer the questions on the following pages before the experiment starts. The questions will help you to understand the experiment. You are allowed to use the instructions. If you need a calculator, you can use the windows calculator or your own calculator. Please rise you hand if you have any questions. The time limit is 10 minutes.

Note:

The comprehension test is available as online supplement.

Part 2 of the experiment was a standard Holt and Laury (2002) risk aversion test. 
Appendix B: Probability-Tables

(Note: The original tables ranged to \pm 20 and \pm 40 respectively)

\begin{tabular}{|c|c|c|c|c|c|c|c|c|c|c|c|c|c|c|c|c|}
\hline$\frac{\text { Value }}{\text { Period }}$ & 0 & 1 & 2 & 3 & 4 & 5 & 6 & 7 & 8 & 9 & 10 & 11 & 12 & 13 & 14 & 15 \\
\hline 0 & 1.000 & & & & & & & & & & & & & & & \\
\hline 1 & 0.000 & 0.500 & & & & & & & & & & & & & & \\
\hline 2 & 0.500 & 0.000 & 0.250 & & & & & & & & & & & & & \\
\hline 3 & 0.000 & 0.375 & 0.000 & 0.125 & & & & & & & & & & & & \\
\hline 4 & 0.375 & 0.000 & 0.250 & 0.000 & 0.063 & & & & & & & & & & & \\
\hline 5 & 0.000 & 0.313 & 0.000 & 0.156 & 0.000 & 0.031 & & & & & & & & & & \\
\hline 6 & 0.313 & 0.000 & 0.234 & 0.000 & 0.094 & 0.000 & 0.016 & & & & & & & & & \\
\hline 7 & 0.000 & 0.273 & 0.000 & 0.164 & 0.000 & 0.055 & 0.000 & 0.008 & & & & & & & & \\
\hline 8 & 0.273 & 0.000 & 0.219 & 0.000 & 0.109 & 0.000 & 0.031 & 0.000 & 0.004 & & & & & & & \\
\hline 9 & 0.000 & 0.246 & 0.000 & 0.164 & 0.000 & 0.070 & 0.000 & 0.018 & 0.000 & 0.002 & & & & & & \\
\hline 10 & 0.246 & 0.000 & 0.205 & 0.000 & 0.117 & 0.000 & 0.044 & 0.000 & 0.010 & 0.000 & 0.001 & & & & & \\
\hline 11 & 0.000 & 0.226 & 0.000 & 0.161 & 0.000 & 0.081 & 0.000 & 0.027 & 0.000 & 0.005 & 0.000 & 0.000 & & & & \\
\hline 12 & 0.226 & 0.000 & 0.193 & 0.000 & 0.121 & 0.000 & 0.054 & 0.000 & 0.016 & 0.000 & 0.003 & 0.000 & 0.000 & & & \\
\hline 13 & 0.000 & 0.209 & 0.000 & 0.157 & 0.000 & 0.087 & 0.000 & 0.035 & 0.000 & 0.010 & 0.000 & 0.002 & 0.000 & 0.000 & & \\
\hline 14 & 0.209 & 0.000 & 0.183 & 0.000 & 0.122 & 0.000 & 0.061 & 0.000 & 0.022 & 0.000 & 0.006 & 0.000 & 0.001 & 0.000 & 0.000 & \\
\hline 15 & 0.000 & 0.196 & 0.000 & 0.153 & 0.000 & 0.092 & 0.000 & 0.042 & 0.000 & 0.014 & 0.000 & 0.003 & 0.000 & 0.000 & 0.000 & 0.000 \\
\hline 16 & 0.196 & 0.000 & 0.175 & 0.000 & 0.122 & 0.000 & 0.067 & 0.000 & 0.028 & 0.000 & 0.009 & 0.000 & 0.002 & 0.000 & 0.000 & 0.000 \\
\hline 17 & 0.000 & 0.185 & 0.000 & 0.148 & 0.000 & 0.094 & 0.000 & 0.047 & 0.000 & 0.018 & 0.000 & 0.005 & 0.000 & 0.001 & 0.000 & 0.000 \\
\hline 18 & 0.185 & 0.000 & 0.167 & 0.000 & 0.121 & 0.000 & 0.071 & 0.000 & 0.033 & 0.000 & 0.012 & 0.000 & 0.003 & 0.000 & 0.001 & 0.000 \\
\hline 19 & 0.000 & 0.176 & 0.000 & 0.144 & 0.000 & 0.096 & 0.000 & 0.052 & 0.000 & 0.022 & 0.000 & 0.007 & 0.000 & 0.002 & 0.000 & 0.000 \\
\hline 20 & 0.176 & 0.000 & 0.160 & 0.000 & 0.120 & 0.000 & 0.074 & 0.000 & 0.037 & 0.000 & 0.015 & 0.000 & 0.005 & 0.000 & 0.001 & 0.000 \\
\hline
\end{tabular}

Figure 1: Probabilities two-step process (positive realizations)

\begin{tabular}{|c|c|c|c|c|c|c|c|c|c|c|c|c|c|c|c|c|}
\hline $\begin{array}{l}\text { Value } \\
\text { Period }\end{array}$ & 0 & -1 & -2 & -3 & -4 & -5 & -6 & -7 & -8 & -9 & -10 & -11 & -12 & -13 & -14 & -15 \\
\hline 0 & 1.000 & & & & & & & & & & & & & & & \\
\hline 1 & 0.000 & 0.500 & & & & & & & & & & & & & & \\
\hline 2 & 0.500 & 0.000 & 0.250 & & & & & & & & & & & & & \\
\hline 3 & 0.000 & 0.375 & 0.000 & 0.125 & & & & & & & & & & & & \\
\hline 4 & 0.375 & 0.000 & 0.250 & 0.000 & 0.063 & & & & & & & & & & & \\
\hline 5 & 0.000 & 0.313 & 0.000 & 0.156 & 0.000 & 0.031 & & & & & & & & & & \\
\hline 6 & 0.313 & 0.000 & 0.234 & 0.000 & 0.094 & 0.000 & 0.016 & & & & & & & & & \\
\hline 7 & 0.000 & 0.273 & 0.000 & 0.164 & 0.000 & 0.055 & 0.000 & 0.008 & & & & & & & & \\
\hline 8 & 0.273 & 0.000 & 0.219 & 0.000 & 0.109 & 0.000 & 0.031 & 0.000 & 0.004 & & & & & & & \\
\hline 9 & 0.000 & 0.246 & 0.000 & 0.164 & 0.000 & 0.070 & 0.000 & 0.018 & 0.000 & 0.002 & & & & & & \\
\hline 10 & 0.246 & 0.000 & 0.205 & 0.000 & 0.117 & 0.000 & 0.044 & 0.000 & 0.010 & 0.000 & 0.001 & & & & & \\
\hline 11 & 0.000 & 0.226 & 0.000 & 0.161 & 0.000 & 0.081 & 0.000 & 0.027 & 0.000 & 0.005 & 0.000 & 0.000 & & & & \\
\hline 12 & 0.226 & 0.000 & 0.193 & 0.000 & 0.121 & 0.000 & 0.054 & 0.000 & 0.016 & 0.000 & 0.003 & 0.000 & 0.000 & & & \\
\hline 13 & 0.000 & 0.209 & 0.000 & 0.157 & 0.000 & 0.087 & 0.000 & 0.035 & 0.000 & 0.010 & 0.000 & 0.002 & 0.000 & 0.000 & & \\
\hline 14 & 0.209 & 0.000 & 0.183 & 0.000 & 0.122 & 0.000 & 0.061 & 0.000 & 0.022 & 0.000 & 0.006 & 0.000 & 0.001 & 0.000 & 0.000 & \\
\hline 15 & 0.000 & 0.196 & 0.000 & 0.153 & 0.000 & 0.092 & 0.000 & 0.042 & 0.000 & 0.014 & 0.000 & 0.003 & 0.000 & 0.000 & 0.000 & 0.000 \\
\hline 16 & 0.196 & 0.000 & 0.175 & 0.000 & 0.122 & 0.000 & 0.067 & 0.000 & 0.028 & 0.000 & 0.009 & 0.000 & 0.002 & 0.000 & 0.000 & 0.000 \\
\hline 17 & 0.000 & 0.185 & 0.000 & 0.148 & 0.000 & 0.094 & 0.000 & 0.047 & 0.000 & 0.018 & 0.000 & 0.005 & 0.000 & 0.001 & 0.000 & 0.000 \\
\hline 18 & 0.185 & 0.000 & 0.167 & 0.000 & 0.121 & 0.000 & 0.071 & 0.000 & 0.033 & 0.000 & 0.012 & 0.000 & 0.003 & 0.000 & 0.001 & 0.000 \\
\hline 19 & 0.000 & 0.176 & 0.000 & 0.144 & 0.000 & 0.096 & 0.000 & 0.052 & 0.000 & 0.022 & 0.000 & 0.007 & 0.000 & 0.002 & 0.000 & 0.000 \\
\hline 20 & 0.176 & 0.000 & 0.160 & 0.000 & 0.120 & 0.000 & 0.074 & 0.000 & 0.037 & 0.000 & 0.015 & 0.000 & 0.005 & 0.000 & 0.001 & 0.000 \\
\hline
\end{tabular}

Figure 2: Probabilities two-step process (negative realizations) 


\begin{tabular}{|c|c|c|c|c|c|c|c|c|c|c|c|c|c|c|c|c|c|c|c|c|c|}
\hline $\begin{array}{l}\text { Value } \\
\text { Period }\end{array}$ & 0 & 1 & 2 & 3 & 4 & 5 & 6 & 7 & 8 & 9 & 10 & 11 & 12 & 13 & 14 & 15 & 16 & 17 & 18 & 19 & 20 \\
\hline 0 & 1.000 & & & & & & & & & & & & & & & & & & & & \\
\hline 1 & 0.200 & 0.200 & 0.200 & & & & & & & & & & & & & & & & & & \\
\hline 2 & 0.200 & 0.160 & 0.120 & 0.080 & 0.040 & & & & & & & & & & & & & & & & \\
\hline 3 & 0.152 & 0.144 & 0.120 & 0.080 & 0.048 & 0.024 & 0.008 & & & & & & & & & & & & & & \\
\hline 4 & 0.136 & 0.128 & 0.109 & 0.083 & 0.056 & 0.032 & 0.016 & 0.006 & 0.002 & & & & & & & & & & & & \\
\hline 5 & 0.122 & 0.117 & 0.102 & 0.082 & 0.059 & 0.039 & 0.022 & 0.011 & 0.005 & 0.002 & 0.000 & & & & & & & & & & \\
\hline 6 & 0.112 & 0.108 & 0.096 & 0.080 & 0.061 & 0.043 & 0.027 & 0.016 & 0.008 & 0.004 & 0.001 & 0.000 & 0.000 & & & & & & & & \\
\hline 7 & 0.104 & 0.101 & 0.091 & 0.078 & 0.061 & 0.045 & 0.031 & 0.019 & 0.011 & 0.006 & 0.003 & 0.001 & 0.000 & 0.000 & 0.000 & & & & & & \\
\hline 8 & 0.098 & 0.095 & 0.087 & 0.075 & 0.061 & 0.047 & 0.034 & 0.023 & 0.014 & 0.008 & 0.004 & 0.002 & 0.001 & 0.000 & 0.000 & 0.000 & 0.000 & & & & \\
\hline 9 & 0.092 & 0.090 & 0.083 & 0.073 & 0.061 & 0.048 & 0.036 & 0.025 & 0.016 & 0.010 & 0.006 & 0.003 & 0.001 & 0.001 & 0.000 & 0.000 & 0.000 & 0.000 & 0.000 & & \\
\hline 10 & 0.088 & 0.086 & 0.080 & 0.071 & 0.060 & 0.049 & 0.037 & 0.027 & 0.019 & 0.012 & 0.007 & 0.004 & 0.002 & 0.001 & 0.001 & 0.000 & 0.000 & 0.000 & 0.000 & 0.000 & 0.000 \\
\hline 11 & 0.084 & 0.082 & 0.077 & 0.069 & 0.059 & 0.049 & 0.038 & 0.029 & 0.020 & 0.014 & 0.009 & 0.005 & 0.003 & 0.002 & 0.001 & 0.000 & 0.000 & 0.000 & 0.000 & 0.000 & 0.000 \\
\hline 12 & 0.080 & 0.079 & 0.074 & 0.067 & 0.058 & 0.049 & 0.039 & 0.030 & 0.022 & 0.015 & 0.010 & 0.007 & 0.004 & 0.002 & 0.001 & 0.001 & 0.000 & 0.000 & 0.000 & 0.000 & 0.000 \\
\hline 13 & 0.077 & 0.076 & 0.072 & 0.066 & 0.058 & 0.049 & 0.040 & 0.031 & 0.023 & 0.017 & 0.012 & 0.008 & 0.005 & 0.003 & 0.002 & 0.001 & 0.000 & 0.000 & 0.000 & 0.000 & 0.000 \\
\hline 14 & 0.075 & 0.073 & 0.070 & 0.064 & 0.057 & 0.049 & 0.040 & 0.032 & 0.025 & 0.018 & 0.013 & 0.009 & 0.006 & 0.004 & 0.002 & 0.001 & 0.001 & 0.000 & 0.000 & 0.000 & 0.000 \\
\hline 15 & 0.072 & 0.071 & 0.068 & 0.062 & 0.056 & 0.048 & 0.040 & 0.033 & 0.026 & 0.019 & 0.014 & 0.010 & 0.007 & 0.004 & 0.003 & 0.002 & 0.001 & 0.001 & 0.000 & 0.000 & 0.000 \\
\hline 16 & 0.070 & 0.069 & 0.066 & 0.061 & 0.055 & 0.048 & 0.041 & 0.033 & 0.026 & 0.020 & 0.015 & 0.011 & 0.008 & 0.005 & 0.003 & 0.002 & 0.001 & 0.001 & 0.000 & 0.000 & 0.000 \\
\hline 17 & 0.068 & 0.067 & 0.064 & 0.060 & 0.054 & 0.047 & 0.041 & 0.034 & 0.027 & 0.021 & 0.016 & 0.012 & 0.008 & 0.006 & 0.004 & 0.002 & 0.002 & 0.001 & 0.001 & 0.000 & 0.000 \\
\hline 18 & 0.066 & 0.065 & 0.062 & 0.058 & 0.053 & 0.047 & 0.041 & 0.034 & 0.028 & 0.022 & 0.017 & 0.013 & 0.009 & 0.006 & 0.004 & 0.003 & 0.002 & 0.001 & 0.001 & 0.000 & 0.000 \\
\hline 19 & 0.064 & 0.063 & 0.061 & 0.057 & 0.052 & 0.047 & 0.041 & 0.034 & 0.028 & 0.023 & 0.018 & 0.013 & 0.010 & 0.007 & 0.005 & 0.003 & 0.002 & 0.001 & 0.001 & 0.000 & 0.000 \\
\hline 20 & 0.063 & 0.062 & 0.060 & 0.056 & 0.052 & 0.046 & 0.040 & 0.034 & 0.029 & 0.023 & 0.018 & 0.014 & 0.011 & 0.008 & 0.005 & 0.004 & 0.003 & 0.002 & 0.001 & 0.001 & 0.000 \\
\hline
\end{tabular}

Figure 3: Probabilities five-step process (positive realizations) 


\begin{tabular}{|c|c|c|c|c|c|c|c|c|c|c|c|c|c|c|c|c|c|c|c|c|c|}
\hline $\begin{array}{l}\text { Value } \\
\text { Period }\end{array}$ & 0 & -1 & -2 & -3 & -4 & -5 & -6 & -7 & -8 & -9 & -10 & -11 & -12 & -13 & -14 & -15 & -16 & -17 & -18 & -19 & -20 \\
\hline 0 & 1.000 & & & & & & & & & & & & & & & & & & & & \\
\hline 1 & 0.200 & 0.200 & 0.200 & & & & & & & & & & & & & & & & & & \\
\hline 2 & 0.200 & 0.160 & 0.120 & 0.080 & 0.040 & & & & & & & & & & & & & & & & \\
\hline 3 & 0.152 & 0.144 & 0.120 & 0.080 & 0.048 & 0.024 & 0.008 & & & & & & & & & & & & & & \\
\hline 4 & 0.136 & 0.128 & 0.109 & 0.083 & 0.056 & 0.032 & 0.016 & 0.006 & 0.002 & & & & & & & & & & & & \\
\hline 5 & 0.122 & 0.117 & 0.102 & 0.082 & 0.059 & 0.039 & 0.022 & 0.011 & 0.005 & 0.002 & 0.000 & & & & & & & & & & \\
\hline 6 & 0.112 & 0.108 & 0.096 & 0.080 & 0.061 & 0.043 & 0.027 & 0.016 & 0.008 & 0.004 & 0.001 & 0.000 & 0.000 & & & & & & & & \\
\hline 7 & 0.104 & 0.101 & 0.091 & 0.078 & 0.061 & 0.045 & 0.031 & 0.019 & 0.011 & 0.006 & 0.003 & 0.001 & 0.000 & 0.000 & 0.000 & & & & & & \\
\hline 8 & 0.098 & 0.095 & 0.087 & 0.075 & 0.061 & 0.047 & 0.034 & 0.023 & 0.014 & 0.008 & 0.004 & 0.002 & 0.001 & 0.000 & 0.000 & 0.000 & 0.000 & & & & \\
\hline 9 & 0.092 & 0.090 & 0.083 & 0.073 & 0.061 & 0.048 & 0.036 & 0.025 & 0.016 & 0.010 & 0.006 & 0.003 & 0.001 & 0.001 & 0.000 & 0.000 & 0.000 & 0.000 & 0.000 & & \\
\hline 10 & 0.088 & 0.086 & 0.080 & 0.071 & 0.060 & 0.049 & 0.037 & 0.027 & 0.019 & 0.012 & 0.007 & 0.004 & 0.002 & 0.001 & 0.001 & 0.000 & 0.000 & 0.000 & 0.000 & 0.000 & 0.000 \\
\hline 11 & 0.084 & 0.082 & 0.077 & 0.069 & 0.059 & 0.049 & 0.038 & 0.029 & 0.020 & 0.014 & 0.009 & 0.005 & 0.003 & 0.002 & 0.001 & 0.000 & 0.000 & 0.000 & 0.000 & 0.000 & 0.000 \\
\hline 12 & 0.080 & 0.079 & 0.074 & 0.067 & 0.058 & 0.049 & 0.039 & 0.030 & 0.022 & 0.015 & 0.010 & 0.007 & 0.004 & 0.002 & 0.001 & 0.001 & 0.000 & 0.000 & 0.000 & 0.000 & 0.000 \\
\hline 13 & 0.077 & 0.076 & 0.072 & 0.066 & 0.058 & 0.049 & 0.040 & 0.031 & 0.023 & 0.017 & 0.012 & 0.008 & 0.005 & 0.003 & 0.002 & 0.001 & 0.000 & 0.000 & 0.000 & 0.000 & 0.000 \\
\hline 14 & 0.075 & 0.073 & 0.070 & 0.064 & 0.057 & 0.049 & 0.040 & 0.032 & 0.025 & 0.018 & 0.013 & 0.009 & 0.006 & 0.004 & 0.002 & 0.001 & 0.001 & 0.000 & 0.000 & 0.000 & 0.000 \\
\hline 15 & 0.072 & 0.071 & 0.068 & 0.062 & 0.056 & 0.048 & 0.040 & 0.033 & 0.026 & 0.019 & 0.014 & 0.010 & 0.007 & 0.004 & 0.003 & 0.002 & 0.001 & 0.001 & 0.000 & 0.000 & 0.000 \\
\hline 16 & 0.070 & 0.069 & 0.066 & 0.061 & 0.055 & 0.048 & 0.041 & 0.033 & 0.026 & 0.020 & 0.015 & 0.011 & 0.008 & 0.005 & 0.003 & 0.002 & 0.001 & 0.001 & 0.000 & 0.000 & 0.000 \\
\hline 17 & 0.068 & 0.067 & 0.064 & 0.060 & 0.054 & 0.047 & 0.041 & 0.034 & 0.027 & 0.021 & 0.016 & 0.012 & 0.008 & 0.006 & 0.004 & 0.002 & 0.002 & 0.001 & 0.001 & 0.000 & 0.000 \\
\hline 18 & 0.066 & 0.065 & 0.062 & 0.058 & 0.053 & 0.047 & 0.041 & 0.034 & 0.028 & 0.022 & 0.017 & 0.013 & 0.009 & 0.006 & 0.004 & 0.003 & 0.002 & 0.001 & 0.001 & 0.000 & 0.000 \\
\hline 19 & 0.064 & 0.063 & 0.061 & 0.057 & 0.052 & 0.047 & 0.041 & 0.034 & 0.028 & 0.023 & 0.018 & 0.013 & 0.010 & 0.007 & 0.005 & 0.003 & 0.002 & 0.001 & 0.001 & 0.000 & 0.000 \\
\hline 20 & 0.063 & 0.062 & 0.060 & 0.056 & 0.052 & 0.046 & 0.040 & 0.034 & 0.029 & 0.023 & 0.018 & 0.014 & 0.011 & 0.008 & 0.005 & 0.004 & 0.003 & 0.002 & 0.001 & 0.001 & 0.000 \\
\hline
\end{tabular}

Figure 4: Probabilities five-step process (negative realizations) 